\title{
MANGO GINGER SUPPLEMENTATION MAY PROTECT BONE DAMAGE INDUCED BY METHOTREXATE IN RATS
}

\author{
FUSUN ERTEN ${ }^{1}$, MEHMET TUZCU는, CEMAL ORHAN ${ }^{2}$, IBRAHIM HANIFI OZERCAN ${ }^{3}$, \\ TANSEL ANSAL BALCI ${ }^{4}$, ZEYNEP TUZCU' ${ }^{1}$, VIJAYA JUTURU ${ }^{5}$ \\ and KAZIM SAHIN*
}

\author{
${ }^{1}$ Department of Biology, Faculty of Science, Firat University, Elazig, Turkey \\ ${ }^{2}$ Department of Animal Nutrition, Faculty of Veterinary Science, Firat University, Elazig, Turkey \\ ${ }^{3}$ Department of Pathology, Faculty of Medicine, Firat University, Elazig, Turkey \\ ${ }^{4}$ Department of Nuclear Medicine, Faculty of Medicine, Firat University, Elazig, Turkey \\ ${ }^{5}$ Research and Development, OmniActive Health Technologies Inc., Morristown, NJ. USA
}

\begin{abstract}
Mango ginger (MG) has anti-inflammatory and antioxidant properties. The objective of this study was to investigate the potential protective role of MG and the mechanisms against methotrexate (MTX) induced bone damage in rats. A total of 28 Sprague-Dawley rats were divided into four groups: i) control; ii) MG, rats were treated orally with $50 \mathrm{mg} / \mathrm{kg} /$ day of MG, iii) MTX, rats were injected with $0.75 \mathrm{mg} / \mathrm{kg}$ of MTX from $8^{\text {th }}$ to $12^{\text {th }}$ day for 5 days and iv) MTX+MG group, rats were treated with $50 \mathrm{mg} / \mathrm{kg} / \mathrm{day}$ of MG and injected with MTX from $8^{\text {th }}$ to $12^{\text {th }}$ day for 5 days. MTX pretreatment increased blood urea nitrogen and creatinine levels and aminotransferase enzyme activities, while tibia osteocalcin levels and bone mineral density (BMD) decreased $(p<0.001)$. MG pretreatment markedly attenuated aminotransferases activities and creatinine levels and increased tibia osteocalcin levels and femur BMD in the MTX + MG groups. MTX treatment increased levels of bone nuclear factor kappa beta ligand receptor-activator (RANKL), interleukin-6 (IL-6) and tumor necrosis factor-alpha $($ TNF- $\alpha)$ and decreased the bone osteoprotegerin (OPG) and type 1 collagen levels $(\mathrm{p}<0.001)$. The effect of MG treatment on RANKL, IL-6, TNF- $\alpha$, OPG and type 1 collagen levels induced by MTX was observed actual effects $(\mathrm{p}<0.05)$. Similarly, the protective effect of MG against MTX was confirmed by histological examination. In conclusion, MG pretreatment reduced the negative effects of MTX on bone damage by improving BMD and modulation of RANKL, IL-6, TNF- $\alpha$, OPG and type 1 collagen expressions in the rats.
\end{abstract}

Keywords: methotrexate, mango ginger, bone mineral density

Chemotherapy has substantial side effects on bone growth and/or bone mineral density (BMD) in bone development $(1,2)$. In addition to many acute injuries resulting from childhood cancer chemotherapy, a decline in BMD outcomes typically in the long-term (2, 3). Methotrexate (MTX), 4-aminoN10-methyl pteroylglutamic acid, an antimetabolite that is structurally alike to folic acid (4) and it hinders the synthesis and repairs of DNA/RNA synthesis and cell proliferation by inhibiting the folate used in purine and thymidine synthesis (5). It was reported that there is a relationship between bone loss caused by MTX and bone remodeling balance and periphery after MTX administration (2, 6). High doses of MTX treatment may cause osteopenia associated with an increase in bone resorption, which increases the likelihood of fracture (7). MTX treat- ment may also reduce bone development due to a decreased bone matrix with osteoblasts and tibial metaphyseal trabecular bone volume, and may increase osteoclast density at the trabecular bone surface (4, 8-10). In addition, MTX administration causes an increase in bone-destroying cytokines that leads to osteoclast change (6).

In combination with chemotherapeutic agents, herbal medicines and chemical inhibitor phytochemicals are effective in minimizing the side effects caused by conventional therapy and sensitizing cancer cells for treatment $(11,12)$. Therefore, natural herbal treatments could reduce the side effects of chemotherapy drugs such as MTX. The genus Curcuma belongs to the Zingiberaceae family, which contains more than 80 species of rhizomatous plants. They originate from the Indo-Malay

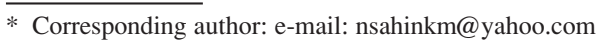


region and are distributed over a wide area from Asia to Africa and Australia to the tropics (13). Curcuma amada Roxb., also known as Mango Ginger (MG), is an important member of the Curcuma family $(14,15)$. MG has rarely been examined as an anticancer treatment in animal models while its many features in Indian medicine have been studied (16). MG exerts both diuretic, antipyretic activity and different medicinal efficacy like as antioxidant, anti-inflammatory, antihyperglycemic, antihypercholesterolemic, antibacterial, antiulcer, and antifungal (17-19). However, no experimental studies have been conducted to evaluate the effects beneficial properties of MG on MTXinduced bone damage and levels of bone TNF- $\alpha$, IL6 , RANKL in a rat model. Therefore, we evaluated the potential protective properties of MG administration on bone loss caused by MTX and the molecular mechanisms by which these effects were shown in rats.

\section{EXPERIMENTAL}

\section{Experimental animals}

Twenty-eight male Sprague-Dawley rats (8 weeks old and body weight $200 \pm 20 \mathrm{~g}$ ) obtained from the Animal Experimental Unit of Firat University were used in the study. Rats were maintained under standard laboratory condition (12/12 h daylight/dark cycles, $55 \pm 5 \%$ relative humidity and $22 \pm 2^{\circ} \mathrm{C}$ temperature). They were fed with a regular diet and tap water ad libitum. The experiment was performed in accordance with the internationally accepted standard ethical guidelines (20) for laboratory animal use and care and permitted by the Ethical Committee of Animal Care of Firat University (2016/18, No:169, Elazig, Turkey).

\section{Animal treatments and experimental protocol}

The rats were divided into four groups of 7 rats each as follows: (i) Control; rats received normal saline by gavage for 15 days and five injections of normal saline subcutaneously (s.c.) on between the $8^{\text {th }}$ and $12^{\text {th }}$ days for 5 days; ii) MG group; rats were treated orally with $50 \mathrm{mg} / \mathrm{kg} /$ day of MG by gavage for 15 days; iii) MTX group, rats received normal saline by gavage for 15 days and 5 injections subcutaneously with $0.75 \mathrm{mg} / \mathrm{kg}$ of MTX from $8^{\text {th }}$ to $12^{\text {th }}$ day for 5 days; and iv) MTX+MG group, rats were treated orally with $50 \mathrm{mg} / \mathrm{kg} /$ day of MG by gavage for 15 days and 5 injections subcutaneously with $0.75 \mathrm{mg} / \mathrm{kg}$ of MTX from $8^{\text {th }}$ to $12^{\text {th }}$ day for 5 days. The dose based on Sahin et al. (21) and King et al. (6) for MG and MTX. Mango ginger was supplied by OmniActive Health Technologies, Inc., Morristown, NJ, USA. Sera and bone samples were collected on day 15 by decapitation in accordance with ethical guidelines (20). Right-left tibia and femurs were separated from soft tissues. Left tibia and femur samples were fixed in $10 \%$ formalin for 24 hours, then decalcified in formic acid-based bone decalcification solution for seven days at $4^{\circ} \mathrm{C}$, and embedded in paraffin wax. Serum and right tibia samples were stored at $-80^{\circ} \mathrm{C}$ until analyzed.

\section{Biochemical analyses}

Concentrations of glucose, cholesterol, and activities of aspartate aminotransferase (AST), alanine aminotransferase (ALT) and levels of blood urea nitrogen (BUN) and creatinine in serum were determined by an autoanalyzer (Samsung Labeo PT10, Samsung Electronics Co., Seoul, Korea) operated by commercial kits.

\section{Osteocalcin}

For osteocalcin analysis, the frozen right tibia was made into a fine powder with mortar and pestle in liquid nitrogen. Then, samples were extracted by sonication in the regulation of investigatory powers act (RIPA) buffer containing protease inhibitors. The homogenates were centrifuged at $15000 \mathrm{rpm}$ for $60 \mathrm{~min}$ at $4^{\circ} \mathrm{C}$. Osteocalcin was measured using the Rat Osteocalcin/Bone (OT/BGP) ELISA Kit (YL Biotech Co., Ltd., Catalog No. YLA0302RA, Shanghai, China) in the supernatants using an ELISA system (Bio-Tek Instruments Inc., VT, USA). The intra and inter-assay coefficients were $3.8 \%$ and $5.5 \%$, respectively.

\section{Bone mineral density}

Tibia and femur tissue BMD were detected by dual-energy X-ray absorptiometry (Lunar Corp., Madison, WI, USA).

\section{Western blot}

Briefly, frozen right tibia tissue was crumpled to a fine powder with mortar and pestle in liquid nitrogen and the samples were extracted by sonication in RIPA buffer containing protease inhibitors (22). After quantification of protein concentrations, the protein samples $(50 \mu \mathrm{g} / \mathrm{lane})$ were separated by SDS-PAGE and moved onto nitrocellulose membranes (Schleicher and Schuell Inc, Keene, NH, USA). After being blocked with $5 \%$ fat-free dry milk, the membranes were incubated with antiRANKL, IL- 6 , TNF- $\alpha$, OPG, and type 1 collagen; Santa Cruz Biotechnology Inc, CA, USA), respectively. After the blots were washed, they were incu- 
bated with secondary antibody (horseradish peroxidase-conjugated goat anti-mouse IgG (Santa Cruz Biotechnology Inc, CA, USA). Protein loading was controlled using $\beta$-actin antibody and protein levels were calculated densitometrically by an image analysis system (Image $\mathrm{J}$, National Institutes of Health, Bethesda, USA).

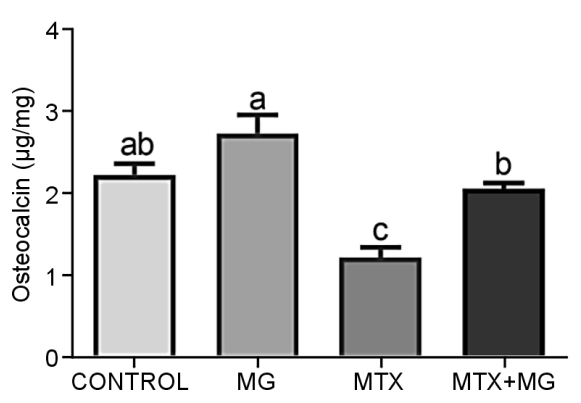

Figure 1. The effects of mango ginger (MG) on levels of osteocalcin in methotrexate (MTX) treated rats. Each bar represents the mean and standard error. Different superscripts $(\mathrm{a}-\mathrm{c})$ indicate group mean differences $(\mathrm{p}<0.05)$

\section{Histopathological examination}

The tibia and femur specimens taken from each experimental animal were fixed in $10 \%$ buffered formalin for $24 \mathrm{~h}$. Calcification in the immunocal solution was then processed for two weeks before the median longitudinal axis splitting and managed for paraffin implanting. Pieces of $4 \mu \mathrm{m}$ thickness were attained, mounted on slides and hematoxylin before being studied under a light microscope. To investigate the treatment effects on bone architecture, trabecular thickness, a number of vessels (intratrabecular area) and osteoclasts count were measured as described (6).

\section{Statistical analysis}

All data expressed in the mean \pm standard error were analyzed by the one-way ANOVA with multiple comparisons Tukey post hoc analysis. Statistical significance was established at $p<0.05$.

\section{RESULTS}

\section{Biochemical parameters}

While MTX treatment alone had a rise in activities of AST, ALT, and blood urea nitrogen and cre-

A
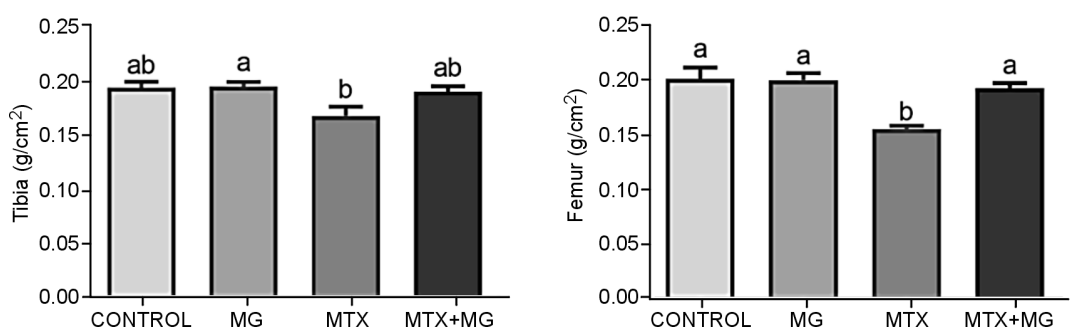

Figure 2. The effects of mango ginger (MG) on bone mineral density levels of the tibia (Panel A) and femur (Panel B) in methotrexate (MTX) treated rats. Each bar represents the mean and standard error. Different superscripts $(\mathrm{a}-\mathrm{b})$ indicate group mean differences $(\mathrm{p}<$ $0.05)$

Table 1. The effects of MG on biochemical parameters in MTX treated rats.

\begin{tabular}{|c|c|c|c|c|}
\hline Item & Control & MG & MTX & MTX + MG \\
\hline Glucose, mg/dL & $119.20 \pm 6.13$ & $109.25 \pm 6.64$ & $113.00 \pm 4.20$ & $97.00 \pm 10.57$ \\
\hline Cholesterol, mg/dL & $84.80 \pm 5.70$ & $79.00 \pm 6.12$ & $93.80 \pm 4.83$ & $83.20 \pm 5.43$ \\
\hline AST, U/L & $104.00 \pm 8.54^{\mathrm{c}}$ & $98.20 \pm 6.18^{\mathrm{c}}$ & $316.80 \pm 7.49^{\mathrm{a}}$ & $209.00 \pm 5.15^{\mathrm{b}}$ \\
\hline ALT, U/L & $56.40 \pm 4.85^{\mathrm{c}}$ & $58.20 \pm 3.89^{\mathrm{c}}$ & $227.80 \pm 6.73^{\mathrm{a}}$ & $176.60 \pm 4.23^{\mathrm{b}}$ \\
\hline BUN, $\mathrm{mg} / \mathrm{dL}$ & $25.54 \pm 1.08^{\mathrm{b}}$ & $24.05 \pm 8.47^{\mathrm{b}}$ & $44.96 \pm 1.77^{\mathrm{a}}$ & $32.74 \pm 1.84^{\mathrm{ab}}$ \\
\hline Creatinine, $\mathrm{mg} / \mathrm{dL}$ & $1.59 \pm 0.07^{\mathrm{b}}$ & $1.58 \pm 0.07^{\mathrm{b}}$ & $1.87 \pm 0.01^{\mathrm{a}}$ & $1.64 \pm 0.02^{\mathrm{b}}$ \\
\hline
\end{tabular}

MG: Mango Ginger MTX: Methotrexate. The difference between the groups with different letters on the same line is statistically significant $(\mathrm{p}<0.05)$ 
atinine concentration compared to control and MG groups, MG treatment caused reductions in these parameters (Table $1 ; p<0.0001$; for all) when compared to the normal controls. AST and ALT levels showed a decrease of 1.5 and 1.3 fold in the MG+MTX group when compared to the MTX group. However, MG alone did not affect these measurements. Additionally, there was no difference in serum cholesterol and glucose levels among all groups.

\section{Bone osteocalcin and bone mineral density}

MTX-exposed rats reflected by low levels of osteocalcin in bone (Fig. $1 ; p<0.0001$ ). However, MG supplementation significantly increased bone osteocalcin concentration $(p<0.001)$ compared to MTX-exposed rats. Compared with the MTX group, osteocalcin levels increased by $55 \%$ in the combination group $(p<0.001)$. Furthermore, there are no changes between control and MG-treated group. As shown in Figure 2, MTX exposure markedly

A
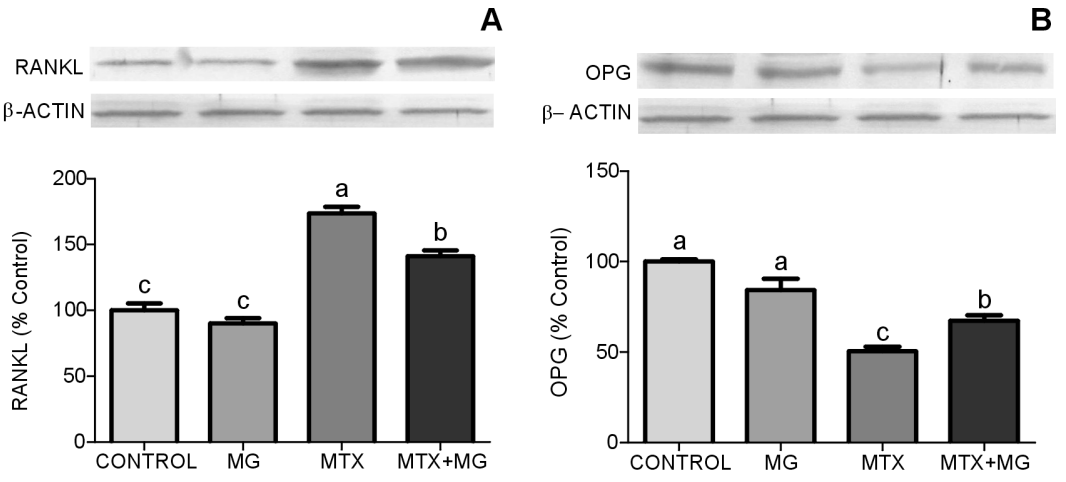

C
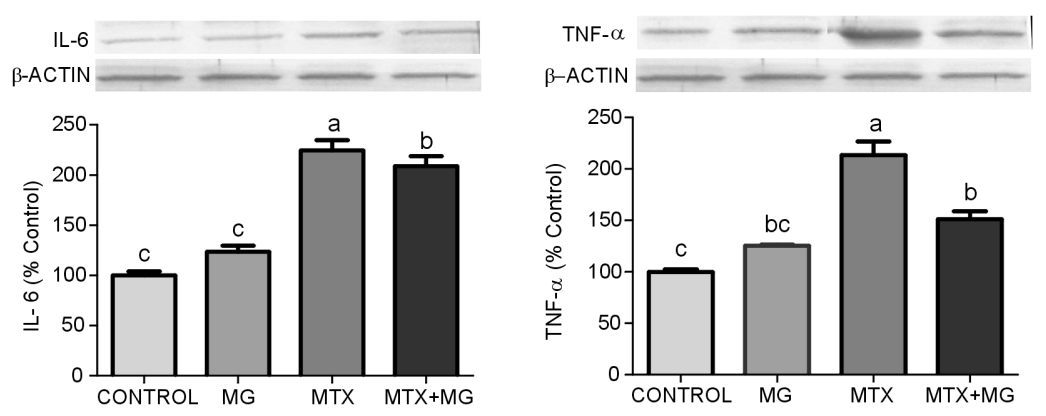

E
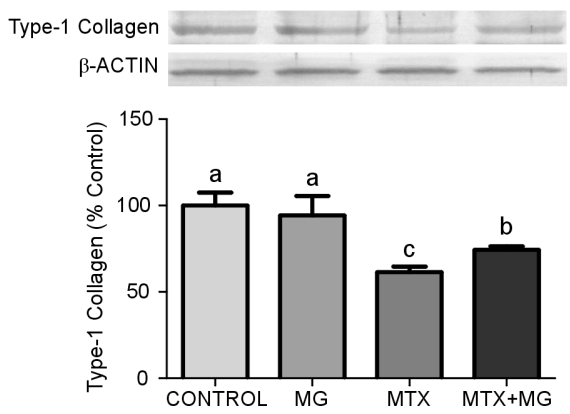

Figure 3. The effects of mango ginger (MG) on protein levels of bone nuclear factor kappa beta ligand receptor-activator (RANKL; Panel A), osteoprotegerin (OPG; Panel B), interleukin-6 (IL-6; Panel C), tumor necrosis factor-alpha (TNF- $\alpha$; Panel D), and type-1 collagen (Panel E) in methotrexate (MTX) treated rats. The intensity of the bands was quantified by densitometric analysis and $\beta$-actin was included to ensure equal protein loading. Data are expressed as percent of the control value. Each bar represents the mean and standard error. Blots were repeated at least 3 times. Different superscripts $(a-c)$ indicate group mean differences $(\mathrm{p}<0.05)$ 

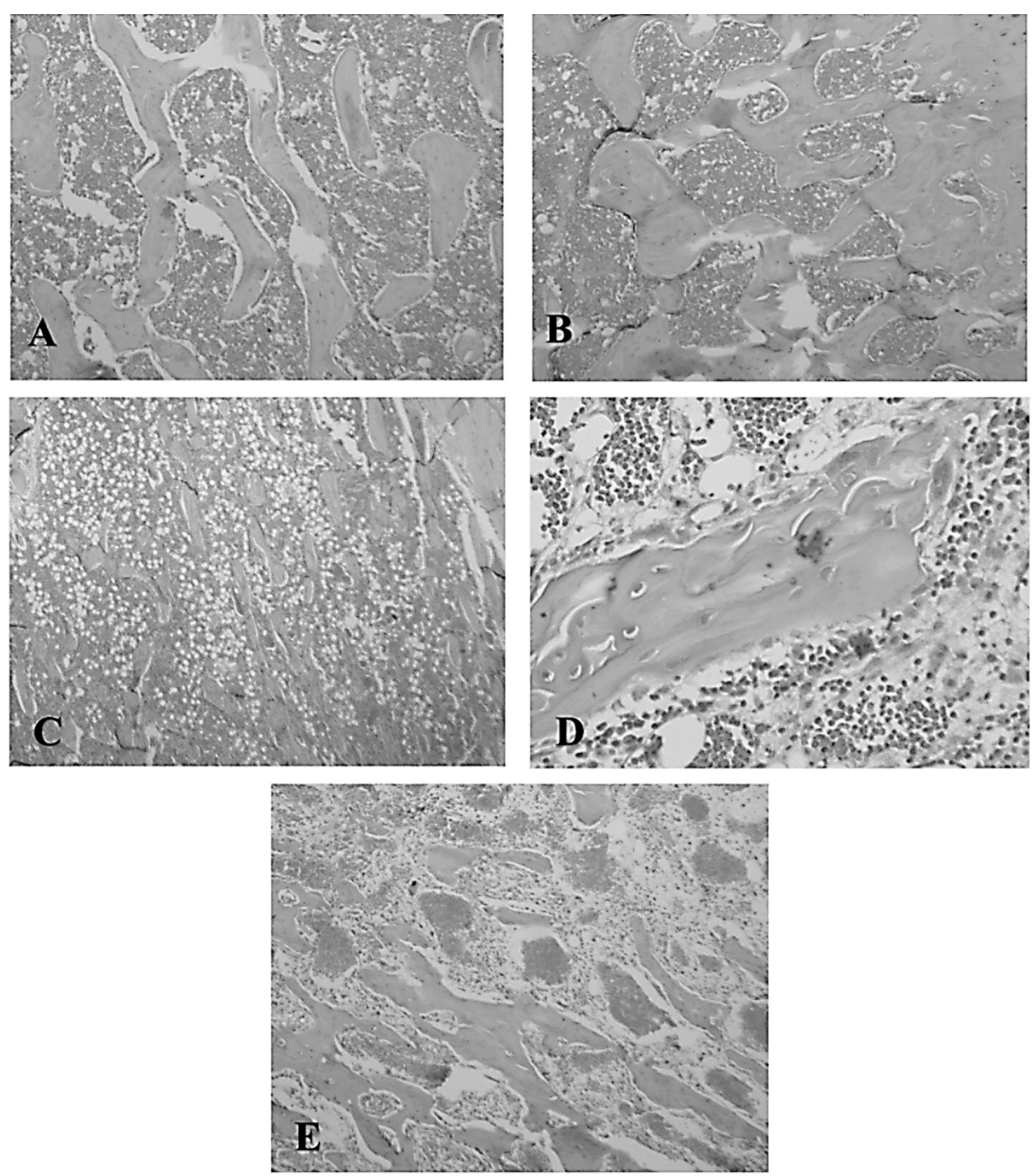

Figure 4. The effects of mango ginger (MG) on histopathologic changes in methotrexate (MTX) treated rats. Bone histopathologic appearance of the groups: A. Control group; B. MG group; C. MTX group; D. Osteoclast formation of the MTX group; E. MTX + MG group, $(\mathrm{H} \& \mathrm{E}, \times 200)$

decreased the tibia and femur BMD in rats (Fig. 2; $p<0.001)$. In contrast, MG pretreatment significantly increased tibia and femur BMD in the MG+MTX group $(p<0.05)$. MG pretreatment alone did not affect BMD compared to rats in the control group.

\section{Bone RANKL, OPG, IL-6, TNF- $\alpha$ and type 1 col- lagen proteins levels}

MTX treatment significantly increased the levels of RANKL, IL- 6 , and TNF- $\alpha$ and decreased the OPG and type-1 collagen in bone compared to the control and MG alone groups (Fig. 3; $p<0.001$ ). However, MG supplementation reduced the RANKL, IL-6, and TNF- $\alpha$ and improved the OPG and type- 1 collagen levels in the MG+MTX group $(p<0.01)$. Compared with the MTX group, a 19\% and $30 \%$ reduction in RANKL and TNF- $\alpha$ protein levels was observed in the MTX + MG group (Fig.
3). Panel A and D; $p<0.001)$. In addition, MG supplementation did not change these protein levels compared to rats in the control group $(p>0.05)$.

\section{Histopathological results}

Significant thinning of bone trabeculae, a marked increase in vessel number and a significant increase in osteoclasts were observed in the bone tissues of the MTX group rats (Fig. 4 and 5). In the group treated with MTX+MG, trabeculae were moderately thinned in the bone tissues, a moderate increase in the number of vessels and osteoclasts (Fig. 4 and 5).

\section{DISCUSSION AND CONCLUSION}

Chemotherapeutic agents, including MTX, cause bone-related defects such as slowed bone 
growth, impaired bone formation, decreased BMD, and increased fractures. $(2,4,6)$. Many studies have emphasized that osteoclasts show a vital role in the understanding of MTX induced bone loss chemotherapy (6-8). Despite the side effects, there are no specific therapies used to reduce the side effects of MTX. In recent years, numerous research has been done on phytochemicals to reduce the side effects of chemotherapy agents $(6,11,12,23)$. Several studies have shown that phytochemicals support the stimulation of bone mass by increasing bone development and decreasing bone mineralization despite the unclear mechanisms $(6,7,23)$. MG has numerous biological activities including antioxidant, anticancer, downregulation of the genes related to inflammation, and cell proliferation and stimulation of apoptosis $(24,25)$. Given the negative effects of MTX on bone and the mechanisms it exhibits, we investigated the effects of MG administration on the changes in BMD and some genes that play an important role in bone metabolism in MTXtreated rats. The current study demonstrated a significantly increased liver and kidney functions and decreased osteocalcin levels and bone mineral density, as well as increased RANKL, IL- 6 , and TNF- $\alpha$ following MTX administration. Nevertheless, MG treatment showed protecting properties against
MTX-induced bone loss by regulation of these parameters in rats. This positive result might apply to its useful property for bone loss due to MTX that induces oxidative stress which motivates the differentiation and proliferation of osteoclasts by cytokine release. In addition, MG might exert its anti-inflammatory effect via diminishing the level of oxidative stress inflammation by regulating nuclear factor kappa B (NF-кB), TNF- $\alpha$, and Nrf2 $(21,26)$. To our best knowledge, the studies on the osteocalcin, BMD, RANKL, IL-6, TNF- $\alpha$, OPG and type- 1 collagen expression in the bone in response to supplementation with MG in MTX treated rats are not available. However, there are many studies similar to the effects of MTX alone in the bone. For example, King et al. (6) reported that MTX increased mRNA interleukin 1 beta (IL-1 1 ) and IL-6 expression in rats. They were also found that RANKL/OPG expression was effective in modulating TNF- $\alpha$, but not in modulating expression ratio. In agreement with the results of the present study, MTX treated up-regulated the ratio of RANKL/OPG mRNA expression and increased the interleukin-1 (IL-1), IL-6 and TNF- $\alpha$ expressions in rats (27). Similarly, Mehrzadi et al. (28) reported that the high dose of MTX induced inflammation in the liver tissue of rats. In a study, it was shown that consecutive

A
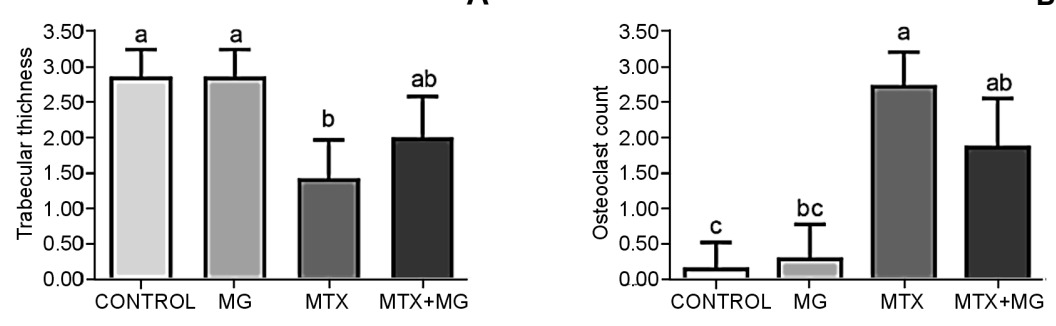

C

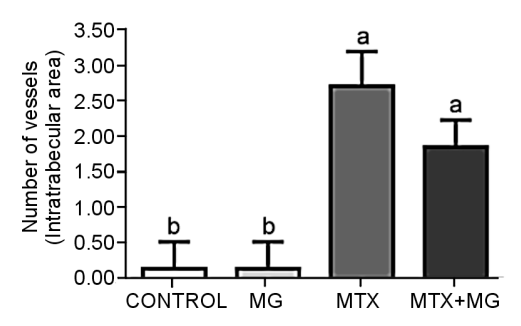

Figure 5. The effects of mango ginger (MG) on histopathologic changes trabecular thickness (Panel A), osteoclasts count (Panel B) and the number of vessels (Intratrabecular area; Panel C) in methotrexate (MTX) treated rats. Each bar represents the mean and standard error. Different superscripts $(\mathrm{a}-\mathrm{c})$ indicate group mean differences $(\mathrm{p}<0.05)$ 
doses of MTX could suppress collagen-II mRNA expression, but could not significantly be suppressed in long-term MTX treated rats (29). Previous studies have shown that multiple mechanisms such as cytokines such as TNF- $\alpha$, IL-1 and IL-6, growth factors, and transcription factors are effective on resorption and bone density in the bone (30). We recently reported that $\mathrm{MG}$ supplementation improves exercise capacity by impairing the signaling of nuclear factor (erythroid-derived 2)-like 2 (Nrf2), heme oxygenase1 (HO-1) and NF- $\mathrm{KB}$ in exercised rats. In addition, RANKL, a receptor activator of the NF- $\mathrm{KB}$ ligand, is responsible for bone resorption (31). The probable mechanism of bone formation in MTX animals is due to oxidative stress produced by the high hydrogen peroxide and lipid peroxidation and reduced antioxidant enzyme activities (32). In addition, Lean et al. (33) reported that oxidative stress might also decrease BMD by inducing TNF- $\alpha$ expression. In a study, it was reported that MG showed activities 1,1diphenyl-2-picrylhydrazyl (DPPH) radical scavenging, superoxide radical scavenging, and lipid peroxidation inhibitory (15). Similarly, MG has been found to reduce muscle lactate, oxidative stress, and to increase muscle antioxidant activity in rats (21). Lee et al. (23) stated that resveratrol, an antioxidant and anti-inflammatory effect such as $\mathrm{MG}$, at $1 \mathrm{mg} / \mathrm{kg}$ well-preserved the growth plate, primary spongiosa, bone volume, and depressed the adipocyte density in MTX-treated rats. It has also been reported that resveratrol can protect the expression levels of osteogenesis-related factors (Runx2, Osx and osteocalcin) in MTX-treated rats (23). Nadhanan et al. (27) observed that fish oil alone (FO) caused an increase in osteocalcin expression and that osteocalcin induction was insignificant in the MTX + FO. In addition, this study has shown that fish oil (medium or high dose) or folinic acid supplementation may improve MTX-induced elevated IL-1, IL-6, and TNF- $\alpha$ expression and RANKL / OPG ratio (27).

The histological results are similarly consistent with the other results of the present study. Consistent with previous results $(6,34)$, MTX caused a reduction in the trabecular thickness and increased the number of osteoclasts and the intratrabecular area in the bone. However, the present findings confirm the protective effect of MG against MTX toxicity in the bone, possibly by reducing the inflammation and the rise of oxidative stress. The antioxidant properties and the anti-inflammatory effect of MG (21) are most likely to affect the membrane-stabilizing effect of MG.

In conclusion, MG is reported to reverse the bone changes by improving osteocalcin and BMD and modulation of RANKL, IL-6, TNF- $\alpha$, OPG and type 1 collagen proteins following MTX treatment in rats. More studies are needed to explain the possible effect of MG as a preventive agent against MTX toxicity.

\section{Acknowledgments}

This work was granted by the Firat University Scientific Research Projects Unit (FF.16.30) and the Turkish Academy of Sciences (K.S.). Authors thank OmniActive Health Technologies Ltd. (India) for providing mango ginger. The authors are thankful to Mr. Besir Er, and Mrs. Hafize Gencaban for their kind efforts during this study.

\section{Conflicts of interest}

The authors declare no conflict of interest. Vijaya Juturu is employed by OmniActive Health Technologies, Inc. in Morristown, NJ, USA.

\section{REFERENCES}

1. Arikoski P., Komulainen J., Riikonen P., Parviainen M., Jurvelin J.S. et al.: J. Bone Miner. Res. 14, 2002 (1999).

2. Pfeilschifter J., Diel I.J.: J. Clin. Oncol. 18, 1570 (2000).

3. Hadji P., Ziller M., Maskow C., Albert U., Kalder M.: Eur. J. Cancer 45, 3205 (2009).

4. Cavalcanti S.C., Corrêa L., Mello S.B., Luz J.G.: J. Craniomaxillofac. Surg. 42, 1133 (2014)

5. Jolivet J., Cowan K.H., Curt G.A., Clendeninn N.J., Chabner B.A.: N. Engl. J. Med. 309, 1094 (1983).

6. King T.J., Shandala T., Lee A.M., Foster B.K., Chen K.M. et al.: Int. J. Mol. Sci. 16, 18293 (2015).

7. Holzer G., Krepler P., Koschat M.A., Grampp S., Dominkus M. et al.: J. Bone Joint. Surg. Br. 85, 231 (2003).

8. May K.P., Mercill D., McDermott M.T., West S.G.: Arthritis Rheum. 39, 489 (1996).

9. Fan C., Cool J.C., Scherer M.A., Foster B.K., Shandala T. et al.: Bone 44, 61 (2009).

10. Xian C.J., Cool J.C., Scherer M.A., Macsai C.E., Fan C. et al.: Bone 41, 842 (2007).

11. Liao G.S., Apaya M.K., Shyur L.F.: Alternat. Med. 2013, 437948 (2013).

12. Tacyildiz N., Ozyoruk D., Yavuz G., Unal E., Dincaslan H. et al.: Nutr. Cancer 62, 1001 (2010). 
13. Sasikumar, B.: Plant Genet. Resour. 3, 230 (2005).

14. Gholap A.S., Bandyopadhyay C.: J. Agric. Food Chem. 32, 57 (1984).

15. Singh G., Singh O.P., de Lampasona M.P., Catalan C.: Indian Perfumer 47, 143 (2003).

16. Hussain A., Virmani O.P., Popli S.P., Misra L.N., Gupta M.M. et al.: Dictionary of Indian Medicinal Plants. p.546, CIMAP, p.546, Lucknow, India 1992.

17. Mujumdar A.M., Naik D.G., Dandge C.N., Puntambekar H.M.: Ind. J. Pharmacol. 32, 375 (2000).

18. Srinivasan M.R., Chandrasekhara N., Srinivasan K.: Eur. Food Res. Technol. 227, 1159 (2008).

19. Singh S., Singh R., Banerjee S., Negi A.S., Shanker K.: Food Chem. 131, 375 (2012).

20. EEC.: OJEU 358, 1 (1986).

21. Sahin K., Tuzcu M., Orhan C., Sahin N., Akdemir F. et al.: FASEB J. 31, 646.18 (2017).

22. Bao Y., Gao Y., Du M., Hou W., Yang L. et al.: Evid. Based Complement. Alternat. Med. 2015, 215892 (2015).

23. Lee A.M., Shandala T., Soo P.P., Su Y.W., King T.J. et al.: Nutrients 9, E255 (2017).

24. Policegoudra R.S., Aradhya S.M., Singh L.: J. Biosci. 36, 739 (2011).
25. Ramachandran C., Portalatin G.M., Prado A.M., Quirin K.W., Escalon E. et al.: J. Evid. Based Complement. Altern. Med. 22, 260 (2017).

26. Policegoudra R.S., Abiraj K., Channe Gowda D., Aradhya S.M.: J. Chromatogr. B Analyt. Technol. Biomed. Life Sci. 852, 40 (2007).

27. Raghu Nadhanan R., Fan C.M., Su Y.W., Howe P.R., Xian C.J.: J. Orthop. Res. 32, 587 (2014).

28. Mehrzadi S., Fatemi I., Esmaeilizadeh M., Ghaznavi H., Kalantar H. et al.: Biomed. Pharmacother. 97, 233 (2018).

29. Fan C.M., Foster B.K., Hui S.K., Xian C.J.: PLoS One 7, e46915 (2012).

30. Raisz L.G.: J. Clin. Invest. 115, 3318 (2005).

31. Boyle W.J., Simonet W.S., Lacey D.L.: Nature 423, 337 (2003).

32. Hussan F., Ibraheem N.G., Kamarudin T.A., Shuid A.N., Soelaiman I.N. et al.: Evid. Based Complement. Alternat. Med. 2012, 174916 (2012).

33. Lean J.M., Jagger C.J., Kirstein B., Fuller K., Chambers T.J.: Endocrinol. 146, 728 (2005).

34. King T.J., Georgiou K.R., Cool J.C., Scherer M.A., Ang E.S. et al.: Am. J. Pathol. 181, 121 (2012).

Received: 5. 10. 2018 